\title{
Comment on "Practice effects in the absolute judgment of frequency" by Heller and Auerbach
}

\author{
LOLA L. CUDDY \\ Queen's University, Kingston, Ont., Canada
}

Heller \& Auerbach (1972) proposed to examine a method developed by Cuddy (1968) for training the absolute judgment of pitch. The present comment provides correction of certain statements in the Heller and Auerbach paper and reemphasizes the need to focus attention on development of a reference standard tone as the basis for structuring pitch judgments.

A recent paper by Heller \& A uerbach (1972), exploring differences in methods for training the absolute judgment of pitch, deserves further procedural and theoretical clarification. Heller and Auerbach are concerned with the finding (Cuddy, 1968) that training recognition of a single reference standard $\left(A_{4}\right.$ or $440 \mathrm{~Hz}$ ) in a series of 10 tones led to improved judgment of all tones in the series, while series training, in which feedback was given for each tone of the series, presented equally often, did not result in improvement. (Heller and Auerbach refer to series training in their paper as a regular feedback condition.) It has been pointed out (Cuddy, 1970) that the results are the opposite of what would be predicted from a model which states that a stimulus-response-reinforcement paradigm is essential for learning.

Several differences between the A-training and series-training methods were outlined by Cuddy (1968); it was noted that further work was needed to identify the factor or factors responsible for the difference in amount of improvement. Heller and Auerbach are not correct, however, to argue that the "shaping" procedure of the A-training method provided Ss with more training than the series-training method. Although the A-training group was presented with a greater proportion of As than other tones in the series, with the proportion decreasing at a rate commensurate with their performance, the A-training group made exactly the same number of judgments during training as did the series-training group. Furthermore, unlike the series-training group, the A-training group received no information regarding the identity of the other tones in the series, other than that they were "not $A$," and it was the finding that their judgment of the entire set of tones was improved that was most interesting theoretically.

It is becoming increasingly apparent (Brady, 1970; Cuddy, 1970) that the development of a subjective reference standard is critical for accurate pitch judgment. Other tones are judged in relation to the subjective reference standard. A musical pitch structure, for instance, can thus be anchored so that judgments correspond to "correct" values. Certain details of the procedure for feedback, e.g., stimulus-feedback overlap, feedback for tones other than the reference, are very likely of considerably less importance than is the requirement of many corrected judgments of a reference tone or tones and a

Table 1

Number of Correct Judgments on Pretest and Posttest for $A$ Train and Series Train Ss (Maximum Possible Score $=80$ )

\begin{tabular}{ccc}
$\begin{array}{c}\text { S } \\
\text { Number }\end{array}$ & $\begin{array}{c}\text { Pretest } \\
\text { Score }\end{array}$ & $\begin{array}{c}\text { Posttest } \\
\text { Score }\end{array}$ \\
\hline \multicolumn{3}{c}{ A Train } \\
1 & 39 & 76 \\
2 & 37 & 79 \\
3 & 30 & 63 \\
4 & 20 & 48 \\
5 & 32 & 57 \\
Mean & 31.6 & 64.6 \\
\multicolumn{4}{c}{ Series Train } & \\
6 & 43 & 37 \\
7 & 34 & 31 \\
8 & 33 & 36 \\
9 & 35 & 21 \\
10 & 19 & 49 \\
Mean & 32.8 & 34.8 \\
\hline
\end{tabular}

detectable structural relation betweer tones (Cuddy, 1971). Thus, it is no1 too surprising to find, as Heller anc Auerbach did, an equivalent amoun of improvement for two groups, botr of whom were trained with an equally high proportion of As and identica stimulus sets.

$A$ final question remains as tc whether or not it was justified tc conclude that $\mathrm{Ss}$ given series training did not improve. Heller and Auerbach suggest that the data reported by Cuddy (1968) were misinterpreted. and that inspection of the original data revealed that four of the five Ss given series training did improve. This statement is incorrect. Examination of the individual $\mathbf{S}$ data, summarized in Table 1 [from Table 17, Cuddy (1965)] shows that thres series-training Ss dropped in accuracy from pre- to posttest, one showed slight improvement, and only one improved to an extent comparable with A training. The null hypothesis of no improvement for the series-training group cannot be rejected. However, the possibility that the results were specific to the highly trained musical population from which the Ss were selected was mentioned (Cuddy, 1968). These Ss obtained an average score of $40 \%$ correct responses on the pretest, a score just slightly higher than that of Heller and Auerbach's Ss on their posttest. The judgment of highly-trained musical listeners may be preexperimentally at a limit which will be exceeded only by some form of reference training. When the criterion for selection of musical Ss is less strict (Cuddy, 1970), improvement following series training is noted, though of lesser degree than that following reference training.

\section{REFERENCES}

BRADY, P. T. Fixed-scale mechanism of absolute pitch. Journal of the Acoustical Society of America, $1970.48,883-887$.

CUDDY, L. L. Practice effects in pitch perception. Unpublished doctoral thesis, University of Toronto, 1965.

CUDDY, L. L. Practice effects in the absolute judgment of pitch. Journal of the Acoustical Society of America, 1968. 43, 1069-1076.

CUDDY, L. L. Training the absolute judgment of pitch. Perception \& Psychophysics, 1970, 8, 265-269.

CUDDY, L L Absolute judgment of musically-related pure tones. Canadian Journal of Psychology, 1971, 25, 42-55.

HELLER, M. A., \& AUERBACH. C. Practice effects in the absolute judgment of frequency. Psychonomic Science, 1972. 26, 222-224. 